\title{
Asymmetric Hydrogenation of Heteroaromatic Compounds
}

\section{YONG-GUI ZHOU*}

Dalian Institute of Chemical Physics, Chinese Academy of Sciences, 457 Zhongshan Road, Dalian 116023, China

Received April 17, 2007

\section{ABSTRACT}

Asymmetric hydrogenation of heteroaromatic compounds has emerged as a promising new route to saturated or partially saturated chiral heterocyclic compounds. In this Account, we outline recent advances in asymmetric hydrogenation of heteroaromatic compounds, including indole, quinoline, isoquinoline, furan, and pyridine derivatives, using chiral organometallic catalysts and organocatalysts.

\section{Introduction}

Catalytic asymmetric hydrogenations of prochiral unsaturated compounds, such as olefins, ketones, and imines, have been intensively studied and are considered a versatile method for access to chiral compounds. ${ }^{1}$ On the other hand, asymmetric hydrogenation of aromatic/ heteroaromatic compounds is much less explored, presumably because of the following reasons: (1) The high stability of aromatic compounds usually requires elevated temperatures and pressures and thereby adversely affecting the enantioselective reduction. ${ }^{2}$ (2) Deactivation and/ or poisoning of catalysts by heteroaromatic compounds containing nitrogen and sulfur atoms may occur. (3) The lack of a secondary coordinating group in simple aromatic compounds, as contrast to functionalized alkenes and ketones, to interact with the central metal atom, must account for the difficulty in achieving enantioselective reactions. ${ }^{1}$ Despite the difficulties cited above, the search for catalysts enabling efficient asymmetric hydrogenation of aromatic/heteroaromatic compounds continues and is driven by the prospect of straightforward and efficient routes to optically active saturated or partially saturated chiral heterocyclic compounds. ${ }^{3}$

The first example of homogeneous asymmetric hydrogenation of aromatic compounds is the 1987 report by Murata and co-workers, who subjected 2-methylquinoxaline under hydrogen in ethanol using $\mathrm{Rh}[(\mathrm{S}, \mathrm{S})-\mathrm{DIOP}] \mathrm{H}$ as the catalyst. A dismal 3\% enantiomeric excess (ee) was obtained (Scheme 1). ${ }^{4}$ A great improvement (50\% ee) was achieved by Takaya and co-workers in 1995, in the hydrogenation of 2-methylfuran ${ }^{5}$ in the presence of [Ru-

\footnotetext{
Yong-Gui Zhou was born in 1970 in Hubei Province, China, received a B.S. degree from Huaibei Coal Industrial Teachers' College in 1993, and earned his Ph.D. degree from Shanghai Institute of Organic Chemistry in 1999, working under the direction of Profs. Li-Xin Dai and Xue-Long Hou. He joined Xumu Zhang's group at the Pennsylvania State University as a postdoctoral fellow that same year and in 2002, he began his independent research career at the Dalian Institute of Chemical Physics, Chinese Academy of Sciences, where he is currently a Professor of chemistry. His research interests include the development of catalytic asymmetric reactions, mechanistic elucidation, and asymmetric synthesis.
}

Scheme 1. Pioneering Works on Asymmetric Hydrogenation of Heteroaromatic Compounds

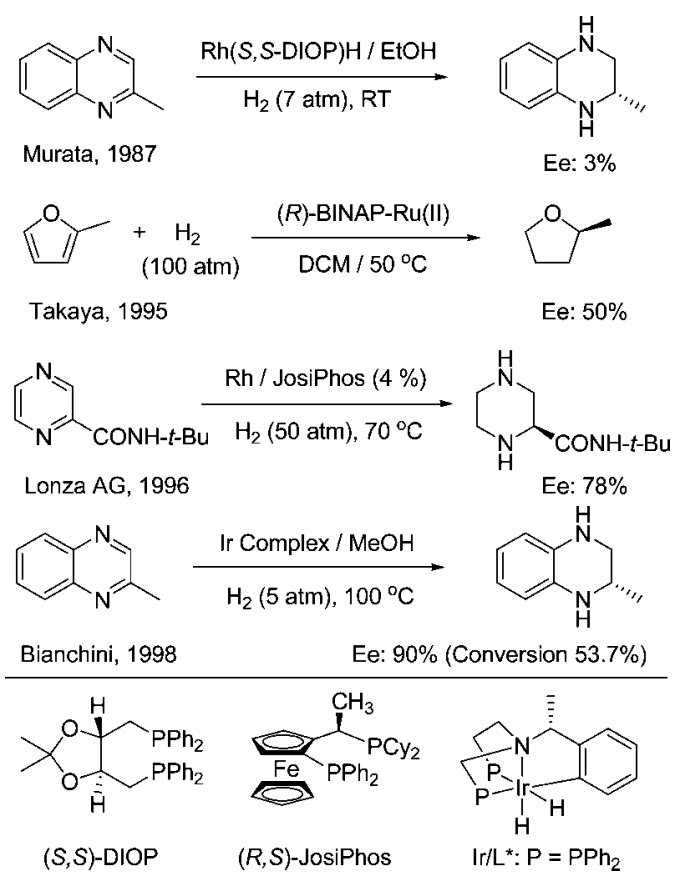

$\mathrm{Cl}(R$-BINAP $\left.)\left(\mu-\mathrm{Cl}_{3}\right)\right]\left[\mathrm{NH}_{2} \mathrm{Et}_{2}\right]$. The patent literature contains the filing ${ }^{6}$ by Lonza AG in 1996 on asymmetric hydrogenation of pyrazinecarboxylic acid derivatives, with an ee up to $78 \%$ using homogeneous $[\mathrm{Rh}(\mathrm{COD}) \mathrm{Cl}]_{2} /$ diphosphine/MeOH at 50 atm. In 1998, Bianchini developed an orthometalated dihydride iridium complex for hydrogenation of 2-methylquinoxaline to 1,2,3,4-tetrahydro-2-methylquinoxaline with up to $90 \%$ ee (Scheme 1 ), ${ }^{7}$ although conversion is not satisfactory. These pioneering works served to demonstrate the feasibility of synthesizing chiral heterocyclic compounds from the corresponding aromatic congeners by asymmetric hydrogenation.

To date, some important advances in homogeneous asymmetric hydrogenation of aromatic/heteroaromatic compounds were achieved using chiral organometallic catalysts and organocatalysts. In this Account, we summarize our efforts in asymmetric hydrogenation of quinolines and isoquinolines and highlight the recent developments in this challenging field by other groups.

A successful asymmetric hydrogenation of aromatic compounds mainly depends upon substrate activation, catalyst activation, and dual activation (Scheme 2). Substrate activation includes the introduction of a secondary coordinating group, activators, and selection of bicyclic aromatic compounds (the aromatic stabilization of the heteroaromatic ring is reduced, thus increasing the reactivity of these substrates toward hydrogenation). Catalyst activation may be achieved by the introduction of certain additives and by the fine tuning of steric and electronic effects of the chiral ligands.

* To whom correspondence should be addressed. Telephone: $(+86)-$ 411-84379220. Fax: (+86)-411-84379220. E-mail: ygzhou@dicp.ac.cn. 
Scheme 2. Strategies for Asymmetric Hydrogenation of Aromatic Compounds

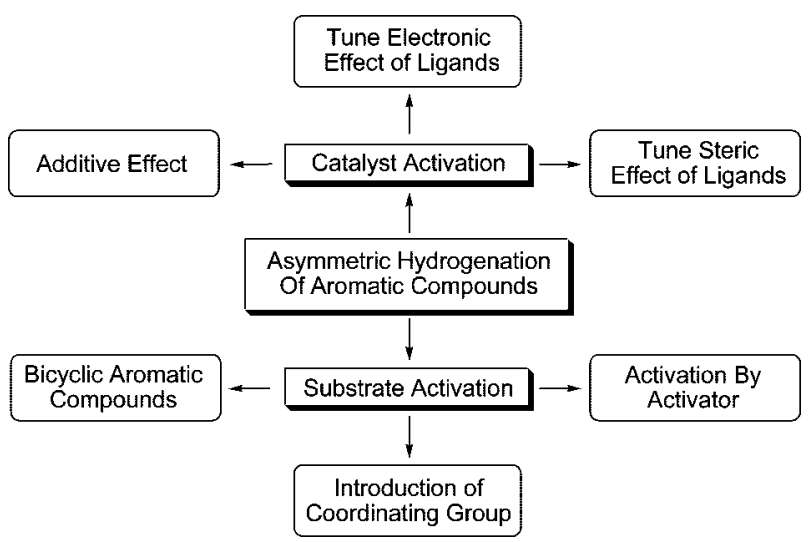

Scheme 3. Strategies for Hydrogenation of Quinolines and Isoquinolines

Strategy I: Highly Reactive Catalyst - Activation of Catalyst

$$
\begin{aligned}
& {[\operatorname{Ir}(\mathrm{COD}) \mathrm{X}]_{2}+\mathrm{L}^{*} \longrightarrow \operatorname{Ir}(\mathrm{COD})\left(\mathrm{L}^{*}\right) \mathrm{X} \stackrel{\text { Activator }}{\longrightarrow} \operatorname{Ir}(I I I)\left(\mathrm{L}^{*}\right) \mathrm{Xn}} \\
& \text { Chiral Ligands Low Reactivity }
\end{aligned}
$$

Strategy II: Activation of Substrates by Activator

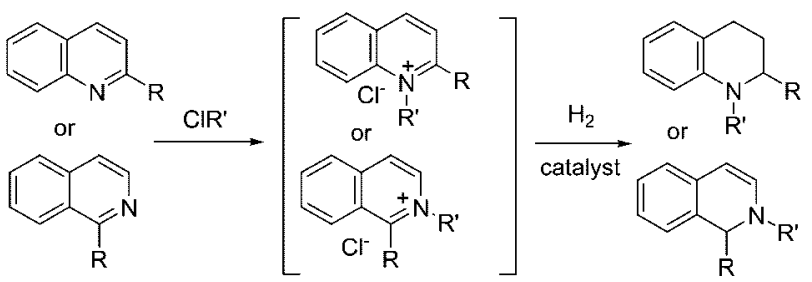

\section{Asymmetric Hydrogenation of Quinoline and Isoquinoline Derivatives}

Direct hydrogenation of easily available quinoline and isoquinoline derivatives is the most convenient route to synthesize the corresponding tetrahydro derivatives, which are important organic synthetic intermediates. Many alkaloids and biologically active compounds contain such structural units. ${ }^{8}$ Surprisingly, no report on homogeneous asymmetric hydrogenation of quinolines and isoquniolines was documented in the literature before we started this program. In our program, two kinds of strategies were considered and implemented for asymmetric hydrogenation of quinolines and isoquinolines: one of which is to develop highly reactive and enantioselective catalysts, and the other concentrates on substrate activation, e.g., by chloroformates (Scheme 3).

Recently, it has been revealed that iridium successfully mediates asymmetric hydrogenation of imines and simple alkenes. ${ }^{1}$ We first examined $[\operatorname{Ir}(\mathrm{COD}) \mathrm{Cl}]_{2} / \mathrm{MeO}$-Biphep, which is the common iridium hydrogenation catalyst, for hydrogenation of 2-methylquinoline. Unfortunately, it was found that the catalytic activity is very low, and only a trace amount of product with low ee was obtained when the reaction was carried out in methylene chloride at room temperature under 700 psi of hydrogen. Although the enantioseletivity and conversion are low, it is demonstrated that asymmetric hydrogenation of quinolines is
Scheme 4. Effect of Additives on Activity and Enantioselectivity
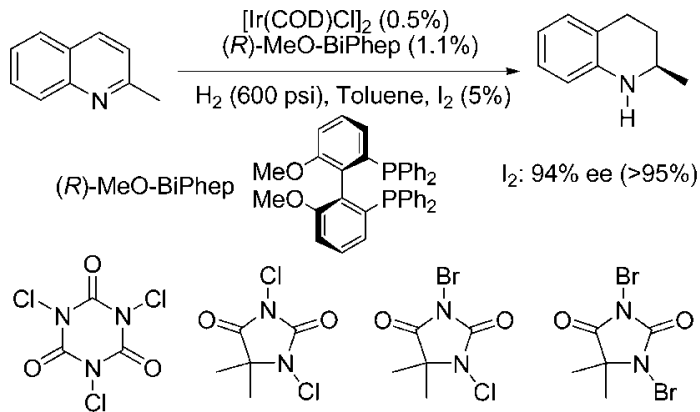

Ee: $89 \%(>95) \quad$ Ee: $91 \%(>95)$ Ee: $92 \%(>95) \quad$ Ee: $92 \%(>95)$

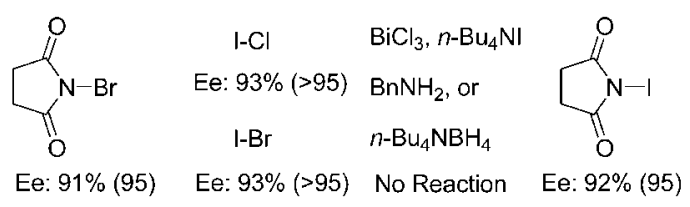

feasible. The next step is how to improve the activity and enantioselectivity. A dramatic impact of additives on catalytic turnover and enantioselectivity was also noted. ${ }^{9}$ For example, iodine increased the reactivity of iridiumcatalyzed asymmetric hydrogenation of imines, ${ }^{10}$ presumably via oxidation of $\operatorname{Ir}^{\mathrm{I}}$ to a more catalytically active $\mathrm{Ir}^{\mathrm{III}}$ state. Following this observation, we explored the highly active $\mathrm{Ir} /(R)$-MeO-BiPhep/I $\mathrm{I}_{2}$ system for asymmetric hydrogenation of quinolines. Using 2-methylquinoline as a model substrate, the reaction proceeded smoothly, affording 2-methyl-1,2,3,4-tetrahydroquinoline with $94 \%$ ee (Scheme 4). ${ }^{11}$ After screening several other additives, we concluded that only iodine and halogen analogues give excellent conversions and enantioselectivity.

Further studies showed a strong solvent dependence in that aprotic solvents, such as toluene, gave the best enantioselectivity (94\%). Other commercially available chiral bidentate phosphine ligands were also examined for the hydrogenation of 2-methylquinoline, and we found that enantioselectivities decreased when (R)-BINAP (87\%), (S)-SynPhos (87\%), (S,S)-DIOP (53\%), or $(R, R)$-Me-DuPhos $(51 \%)$ was used instead of MeO-BiPhep (94\% ee) or $(S)$ SegPhos (94\%). Thus, the optimal conditions that we established involve $[\operatorname{Ir}(\mathrm{COD}) \mathrm{Cl}]_{2} / \mathrm{MeO}-\mathrm{BiPhep} / \mathrm{I}_{2}$ in toluene at 700 psi of $\mathrm{H}_{2}$ (Figure 1).

A variety of substituted quinoline derivatives were hydrogenated using $\mathrm{Ir} / \mathrm{MeO}-\mathrm{Biphep} / \mathrm{I}_{2}$ as the catalyst system. Several 2-alkyl-substituted quinolines were hydrogenated with high enantioselctivities $(>92 \%$ ee), regardless of the length of the side chain (entries 1-6 in Table 1). 2-Arenethyl-substituted quinolines also gave excellent asymmetric induction (entries 8-10). 2-Aryl- and 2-hydroxymethyl quinolines showed lower enantioselectivities (entries 14 and 18). While this catalytic system can tolerate hydroxyl and ester groups (entries 15-19 and 24), a $\mathrm{C}=\mathrm{C}$ double bond in the side chain of the substrate (entries 5 and 21) was saturated. From the fact that threeand four-substituted quinolines gave essentially racemic products ( 0 and $1 \%$ ee for 3 - and 4-methylquinoline, respectively) strongly indicates an intimate involvement of the heterocyclic nitrogen atom in forming intermediates 


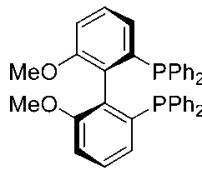

(R)-MeO-BiPhep Ee: $94 \%(>95 \%)$

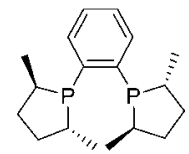

$(R, R)$-Me-DuPhos Ee: $51 \%(90 \%)$

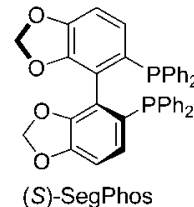

(S)-SegPhos
Ee: $94 \%(>95 \%)$

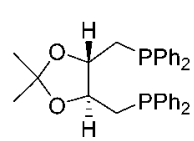

(S,S)-DIOP Ee: $53 \%(15 \%)$

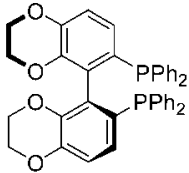

(S)-SynPhos

Ee: $87 \%(>95 \%)$

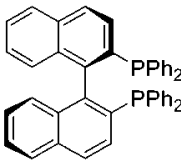

(R)-BINAP Ee: $87 \%(>95 \%)$
FIGURE 1. Effect of ligands on conversion and ee.

Table 1. Ir-Catalyzed Asymmetric Hydrogenation of Quinolines

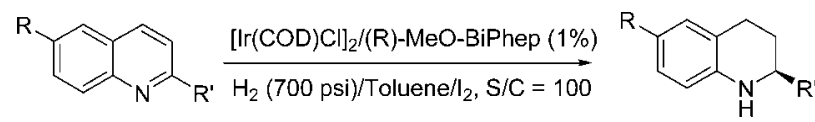

\begin{tabular}{|c|c|c|c|}
\hline entry & $\mathrm{R} / \mathrm{R}^{\prime}$ & yield $(\%)$ & ee $(\%)$ \\
\hline 1 & $\mathrm{H} / \mathrm{Me}$ & 94 & $94(h$ \\
\hline 2 & $\mathrm{H} / \mathrm{Et}$ & 88 & $96(I$ \\
\hline 3 & $\mathrm{H} / n-\mathrm{Pr}$ & 92 & 93( \\
\hline 4 & $\mathrm{H} / n-\mathrm{Bu}$ & 86 & $92(h$ \\
\hline 5 & $\mathrm{H} / 3$-butenyl & $91^{a}$ & 92( \\
\hline 6 & $\mathrm{H} / n$-pentyl & 92 & $94(H$ \\
\hline 7 & $\mathrm{H} / i-\mathrm{Pr}$ & 92 & $94(S$ \\
\hline 8 & H/phenethyl & 94 & $93(h$ \\
\hline 9 & H/3,4-methylenedioxyphenethyl & 88 & $93(I$ \\
\hline 10 & $\mathrm{H} / 3,4-(\mathrm{MeO})_{2} \mathrm{C}_{6} \mathrm{H}_{3}\left(\mathrm{CH}_{2}\right)_{2}-$ & 86 & $96(h$ \\
\hline 11 & $\mathrm{~F} / \mathrm{Me}$ & 88 & $96(I$ \\
\hline 12 & $\mathrm{Me} / \mathrm{Me}$ & 91 & 91( \\
\hline 13 & $\mathrm{MeO} / \mathrm{Me}$ & 89 & $84(1$ \\
\hline 14 & $\mathrm{H} / \mathrm{Ph}$ & 95 & $72(S)$ \\
\hline 15 & $\mathrm{H} / \mathrm{Me}_{2} \mathrm{CH}(\mathrm{OH}) \mathrm{CH}_{2}-$ & 87 & $94(S$ \\
\hline 16 & $\mathrm{H} / c-\mathrm{C}_{6} \mathrm{H}_{11}(\mathrm{OH}) \mathrm{CH}_{2}-$ & 89 & $92(S)$ \\
\hline 17 & $\mathrm{H} / \mathrm{Ph}_{2} \mathrm{CH}(\mathrm{OH}) \mathrm{CH}_{2}-$ & 94 & $91(S)$ \\
\hline 18 & $\mathrm{H} / \mathrm{CH}_{2} \mathrm{OH}^{b}$ & 83 & $75(S$ \\
\hline 19 & $\mathrm{H} / \mathrm{CH}_{2} \mathrm{OCOCH}_{3}$ & 90 & $87(S$ \\
\hline 20 & $\mathrm{H} / \mathrm{CH}_{2} \mathrm{OPh}$ & 90 & $93(S)$ \\
\hline 21 & $\mathrm{H} / 4-\mathrm{MeOC}_{6} \mathrm{H}_{4} \mathrm{CH}=\mathrm{CH}$ & $80^{a}$ & 95( \\
\hline 22 & $\mathrm{H} /\left(\mathrm{CH}_{2}\right)_{3} \mathrm{OBn}$ & 62 & $94(R)$ \\
\hline 23 & $\mathrm{H} /\left(\mathrm{CH}_{2}\right)_{4} \mathrm{OBn}$ & 84 & $93(R)$ \\
\hline 24 & $\mathrm{H} / \mathrm{CH}_{2} \mathrm{CO}_{2} \mathrm{Me}$ & 90 & $92(S$ \\
\hline
\end{tabular}

${ }^{a} \mathrm{C}=\mathrm{C}$ of the side chain was hydrogenated. ${ }^{b} i$-PrOH was used as the solvent.

prior to hydrogen transfer; therefore, only a prochiral C-2 would have stereochemical consequences.

Ir complexes with ferrocene-based N-P and S-P ligands also promote asymmetric hydrogenation of quinolines (Scheme 5). ${ }^{12 a, b}$ Using the one with a N-P ligand, tetrahydroquinolines of up to $90 \%$ ee were obtained. Central chirality determined the absolute configuration of the products in iridium-ferrocenyloxazoline catalytic systems with planar chirality. For S-P ligands, S-P-1 and S-P-2 with the same central chirality and opposite planar chirality gave a product with the same absolute configuration. Interestingly, if a bulky trimethylsilyl (TMS) group (S-P-3 and S-P-4) was introduced to the $\mathrm{Cp}$ ring of S-P-1 and S-P-2 ligands, hydrogenation products with opposite absolute configuration were obtained in high enantioselectivity. It is noted that hydrogenation of quinolines can also proceed smoothly in air using $\left[\mathrm{Ru}\left(p \text {-cymene) } \mathrm{Cl}_{2}\right]_{2} / \mathrm{I}_{2} /\right.$ tetrahydrofuran (THF) as the
Scheme 5. Asymmetric Hydrogenation of Quinolines using Ferrocene Derived N-P and S-P Ligands
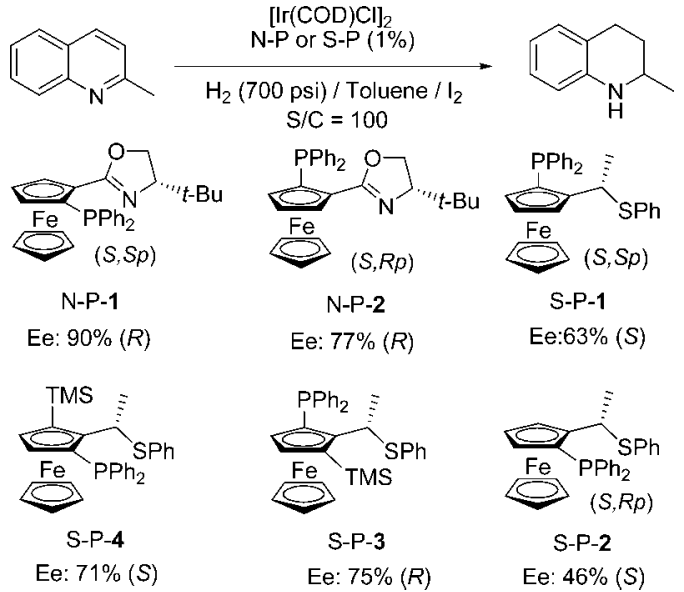

catalytic system with high catalytic activity [turnover number of the reaction (TON) of up to 20000$],{ }^{12 \mathrm{c}}$ but the asymmetric version gave very low enantioselectivity using the chiral diphosphine ligands or diamine ligands.

Iridium-catalyzed asymmetric hydrogenation of quinolines provides a convenient and economical route to synthesize optically active tetrahydroquinolines. This methodology can be successfully applied to the asymmetric synthesis of tetrahydroquinoline alkaloids and chiral drugs (Scheme 6). ${ }^{11,13}$ For example, the hydrogenation product of 6-fluoro-2-methylquinoline is the key intermediate of the antibacterial agent of Flumequine. $\mathrm{N}$-Methylation of hydrogenation products completed the synthesis of angustrureine, galipinine, and cuspareine in high total yields. A seven-step synthesis of (-)-galipeine that contains a free phenol hydroxyl group was accomplished from isovanillin with a $54 \%$ overall yield, and the work enabled an assignment of its absolute configuration. ${ }^{13}$ Similarly, absolute configurations of $(+)$-angustureine, $(-)$-galipinine, and $(-)$-galipeine were assigned through our synthesis.

Intense research activities are evident in metal-free enantioselective transfer hydrogenation of $\alpha, \beta$-unsaturated carbonyl compounds and imines using organocatalysts with Hantzsch esters as the hydrogen source. ${ }^{14}$ In 2006, Rueping extended this strategy to reduce quinolines, ${ }^{15}$ employing sterically congested chiral BINOL-phosphoric acids. This reaction was found to be highly solventdependent, in which nonpolar (e.g., benzene) gave the best enantioselectivity. Under optimal conditions, excellent enantioselectivities (87-99\% ee) were obtained for 2 -substituted quinolines (Scheme 7). A possible reaction mechanism indicates the protonation of the quinolines by the chiral phosphoric acid, which allows for a 1,4dihydride addition, isomerization, and 1,2-hydride addition to give the desirable tetrahydroquinolines.

Our recent discovery that Hantzsch esters could be dehydrogenated using the $[\operatorname{Ir}(\mathrm{COD}) \mathrm{Cl}]_{2} /$ phosphine $/ \mathrm{I}_{2}$ system ${ }^{16}$ led to an exploration of quinoline reduction. We were glad to observe that hydrogenation can proceed smoothly using $[\mathrm{Ir}(\mathrm{COD}) \mathrm{Cl}]_{2} /(S)$-SegPhos $/ \mathrm{I}_{2}$ with $10-88 \%$ ee (Scheme 8). ${ }^{17}$ 
Scheme 6. Asymmetric Synthesis of Tetrahydroquinoline Alkaloids and Drugs

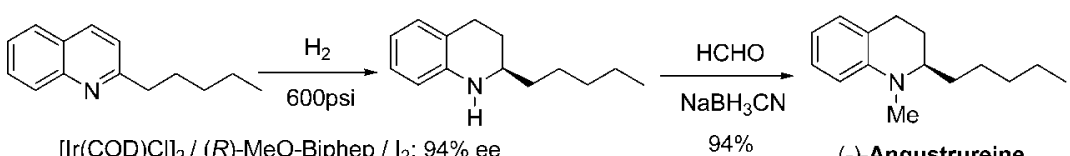

$[\operatorname{lr}(\mathrm{COD}) \mathrm{Cl}]_{2} /(R)$-MeO-Biphep $/ \mathrm{I}_{2}: 94 \%$ ee

(-)-Angustrureine<smiles>CN1c2ccccc2CC[C@@H]1CCc1ccc2c(c1)OCO2</smiles>

(-)-Galipinine<smiles>C[C@H]1CCc2cc(F)cc3c(=O)c(C(=O)O)cn1c23</smiles>

(S)-Flumequine<smiles>COc1ccc(CC[C@@H]2CCc3ccccc3N2C)cc1OC</smiles>

(-)-Cuspareine

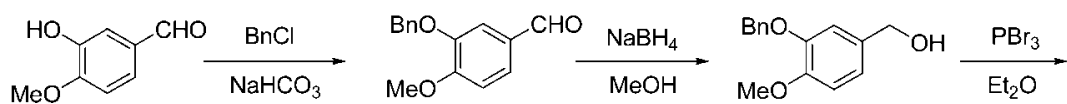

Isovanillin

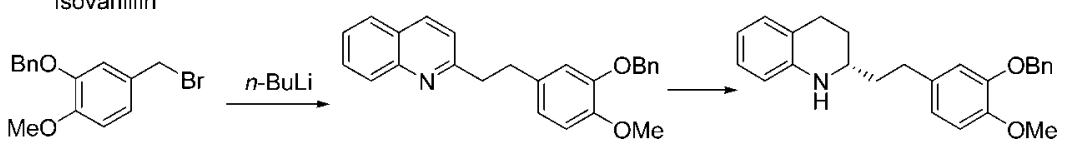

[Ir(COD)Cl $]_{2} /(S)$-MeO-Biphep / $\mathrm{H}_{2}(500 \mathrm{psi}) / \mathrm{I}_{2}: 96 \%$ ee

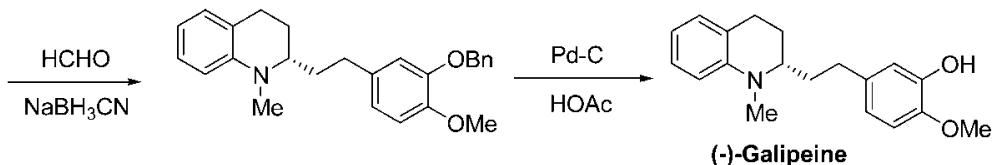

Scheme 7. First Organocatalytic Hydrogenation of Quinolines<smiles>[R]c1ccc2nc([R])ccc2c1</smiles>

16 Examples
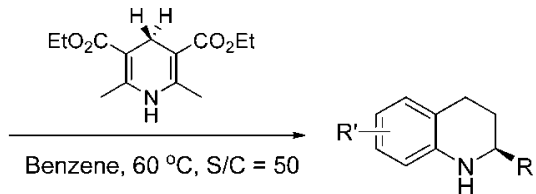

$$
\text { Ee: 88->99\% }
$$

Scheme 8. Asymmetric Transfer Hydrogenation of Quinolines<smiles>CCOC(=O)C1=C(C)NC(C)=C(C(OCC)OCC)[C@H]1[10CH3]</smiles>

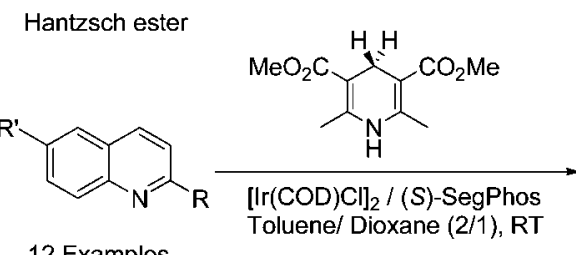

12 Examples

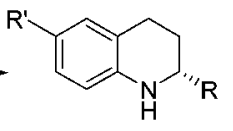

Ee: $10-88 \%$

A natural extension of our work is to hydrogenate isoquinolines, but unfortunately the results were disappointing. We attribute the lack of reactivity to a high affinity of the hydrogenation products of isoquinolines, so that the chiral metal catalyst was not released. Accordingly, substrate modification should overcome the turnover problem. The selection of alkyl chloroformates as the modifiers is based on the following reasons (Scheme 9): (1) Aromaticity was destroyed partially by the formation of quinolinium and isoquinolinium salts. (2) Removing the
Scheme 9. Hydrogenation of Quinolines and Isoquinolines Activated by Chloroformates<smiles>[R]OC(=O)N1C=Cc2ccccc2C1[R]</smiles>

lone-pair electrons from the $\mathrm{N}$ atom avoids strong binding to the metal center. (3) Attached $\mathrm{CO}_{2} \mathrm{R}$ is probably important for the coordination between the substrate and catalyst.

The mechanism analysis indicated that 1 equiv of hydrogen chloride was produced during hydrogenation of quinolines and isoquinolines activated by chloroformates, which might block the reaction by the formation of the $\mathrm{HCl}$ salt of quinolines or isoquinolines. Therefore, the addition of a base to neutralize hydrogen chloride is necessary for substrate use. A survey of the base/solvent profile revealed that the combination of $\mathrm{Li}_{2} \mathrm{CO}_{3}$ and THF could give complete conversion. Besides alkyl chloroformates, we examined benzoyl chloride, acetyl chloride, and acetic anhydride as alternatives, but they were inefficient. Our studies also included the screening of other commercially available chiral ligands; among them, (S)-SegPhos gave the best enantioselectivity. A variety of 2-substituted quinolines were hydrogenated using $\mathrm{Ir} /(S)$-SegPhos/ $\mathrm{ClCO}_{2} \mathrm{Bn} / \mathrm{Li}_{2} \mathrm{CO}_{3} /$ THF with $80-90 \%$ ee (Table 2 ), ${ }^{18}$ among which only 2-phenylquinoline gave lower conversion and enantioselectivity ( $41 \%$ yield and $80 \%$ ee).

Extension of the work to asymmetric hydrogenation of isoquinolines resulted in only partially hydrogenated 1,2dihydroisoquinoline. In the case of 1-methylisoquinoline, 
Table 2. Hydrogenation of Quinolines Activated by $\mathrm{ClCO}_{2} \mathrm{Bn}$

\begin{tabular}{|c|c|c|c|}
\hline entry & $\mathrm{R}^{\prime} / \mathrm{R}$ & yield $(\%)$ & ee $(\%)$ \\
\hline 1 & $\mathrm{H} / \mathrm{Me}$ & 90 & $90(S)$ \\
\hline 2 & $\mathrm{H} / \mathrm{Et}$ & 85 & $90(S)$ \\
\hline 3 & $\mathrm{H} / n-\mathrm{Pr}$ & 80 & $90(S)$ \\
\hline 4 & $\mathrm{H} / n-\mathrm{Bu}$ & 88 & $89(S)$ \\
\hline 5 & $\mathrm{H} / n$-pentyl & 91 & $89(S)$ \\
\hline 6 & $\mathrm{~F} / \mathrm{Me}$ & 83 & $89(S)$ \\
\hline 7 & $\mathrm{Me} / \mathrm{Me}$ & 90 & $89(S)$ \\
\hline 8 & $\mathrm{MeO} / \mathrm{Me}^{a}$ & 92 & $90(S)$ \\
\hline 9 & $\mathrm{H} / \mathrm{Ph}$ & 41 & $80(R)$ \\
\hline 10 & H/phenethyl & 86 & $90(S)$ \\
\hline 11 & $\mathrm{H} / 3,4-(\mathrm{MeO})_{2} \mathrm{C}_{6} \mathrm{H}_{3}\left(\mathrm{CH}_{2}\right)_{2}$ & 80 & $90(S)$ \\
\hline 12 & $\mathrm{H} / 3-\mathrm{MeO}-4-\mathrm{BnOC}_{6} \mathrm{H}_{3}\left(\mathrm{CH}_{2}\right)_{2}$ & 88 & $88(S)$ \\
\hline
\end{tabular}

${ }^{a}$ Reaction at $50{ }^{\circ} \mathrm{C}$.

Scheme 10. Asymmetric Hydrogenation of Isoquinolines

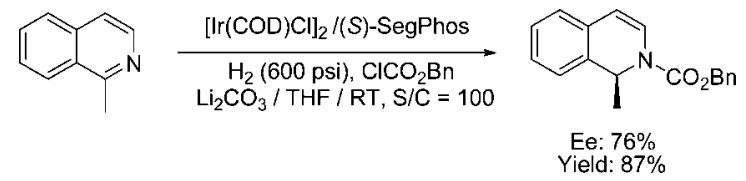

Table 3. Asymmetric Hydrogenation of Isoquinolines

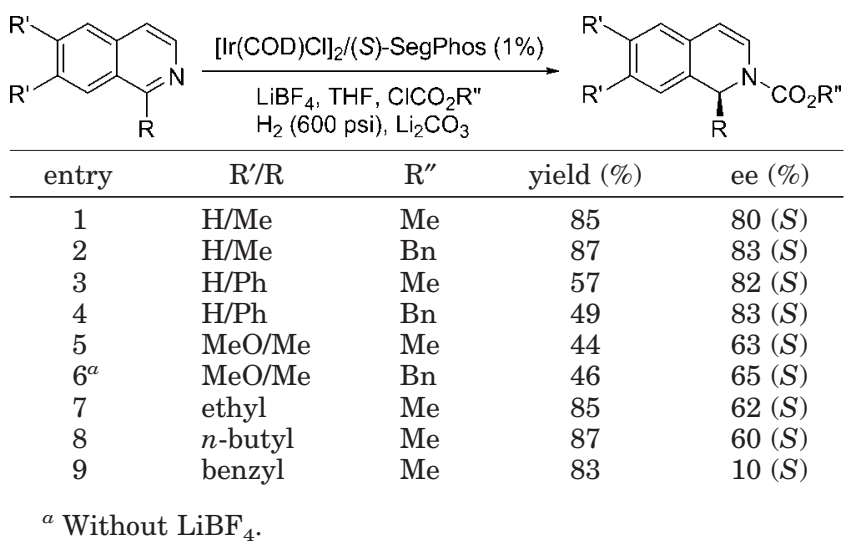

the partially hydrogenated product was obtained in $87 \%$ yield with $76 \%$ ee under the above conditions, using $(S)$ SegPhos as the ligand (Scheme 10). The reaction did not occur in the absence of benzyl chloroformate.

Because an equivalent of $\mathrm{LiCl}$ was produced during this reaction, the effect of lithium salt with different counterions on the enantioselectivity was investigated. The results showed that the ee slightly increased $(76-83 \%$ ee) in the presence of $\mathrm{LiBF}_{4}$ or LiOTf. Ligand screening indicated that $(S)$-SegPhos gave the best enantioselectivity ( $83 \%$ ee).

Results from the hydrogenation of isoquinolines are collected in Table 3. 1-Alkylisoquinolines were hydrogenated with moderate to good enantioselectivities regardless of the length of the alkyl chain (entries 1-4 and 7-8). As for 1-phenylisoquinoline, excellent enantioselectivity was obtained but the conversion was moderate, which might be due to the steric effect of the bulky phenyl group. Low enantioselectivity was obtained for 1-benzylisoquino- line $(10 \%$ ee, entry 9$)$. It is noted that this is the first example for the asymmetric hydrogenation of isoquinoline derivatives.

Thus, asymmetric hydrogenation of quinolines and isoquinolines activated by chloroformates provides a convenient route to synthesize optically active quinoline and isoquinoline alkaloids (Scheme 10). ${ }^{18}$ For instance, the reduction of hydrogenation products with $\mathrm{LiAlH}_{4}$ in $\mathrm{Et}_{2} \mathrm{O}$ afforded the $\mathrm{N}$-methylation products in high yield, which are the naturally occurring tetrahydroquinoline alkaloids. Similarly, naturally occurring tetrahydroisoquinoline alkaloids were synthesized in three steps starting from isoquinolines (Scheme 11). For example, (S)-(-)carnegine can be synthesized by asymmetric hydrogenation, $\mathrm{Pd}-\mathrm{C}$ hydrogenation, and $\mathrm{LiAlH}_{4}$ reduction.

Since we reported our initial work on iridium-catalyzed enantioselective hydrogenation of quinoline derivatives in the presence of $\mathrm{I}_{2},{ }^{11}$ several other groups have communicated their results in this area. ${ }^{19-24}$ Chiral bisphosphine ligands have been designed and tested. Some representative examples are shown in Figure 2.

Fan, Chan, and co-workers have developed a highly effective and air-stable catalyst system Ir/P-Phos/ $\mathrm{I}_{2}$ for the asymmetric hydrogenation of quinoline derivatives with $90-92 \%$ ee. ${ }^{19}$ Moreover, this catalyst can be efficiently immobilized in poly(ethylene glycol) dimethyl ether (DMPEG), which retained reactivity and enantioselectivity in eight runs. $\mathrm{Xu}, \mathrm{Fan}, \mathrm{Chan}$, and co-workers found that the Ir-H8-BINAPO catalyst and Ir complexes with chiral diphosphinite ligands based on a 1,1'-spirobiindane backbone were highly effective. ${ }^{20}$ Using DMPEG/hexane as the reaction medium, up to $97 \%$ ee was obtained, but those catalysts are difficult to recycle. In 2006, Chan and coworkers reported the asymmetric hydrogenation of quinolines in $92 \%$ ee with their Ir/PQ-Phos. ${ }^{21}$ Reetz and coworkers found that chiral BINOL-derived diphosphonites further linked to an achiral diphenyl ether unit were also effective ligands (73-96\% ee). ${ }^{22}$ Iridium-catalyzed asymmetric hydrogenation of quinolines in the presence of iodine required high catalyst loading, which may be due to the catalyst deactivation during the reaction. It was reported that the Ir complexes could form an inactive dimer irreversibly. This notion finds some support in that encapsulation of the iridium complex in a dendrimer framework reduced dimerization [(S)-GnDenBINAP], ensuing high enantioselectivities and significantly high catalytic activities [turnover frequency (TOF) of up to 3450 $\mathrm{h}^{-1}$ ] and productivities (TON of up to 43000 ). ${ }^{23}$ Such a catalyst could be recovered simply by precipitation and filtration for reuse at least 6 times while maintaining comparable enantioselectivity. These exciting developments demonstrate perfectly that $\mathrm{Ir} / \mathrm{phosphine} / \mathrm{I}_{2}$ is an excellent catalytic system for asymmetric hydrogenation of quinolines. 
Scheme 11. Asymmetric Synthesis of Quinoline and Isoquinoline Alkaloids

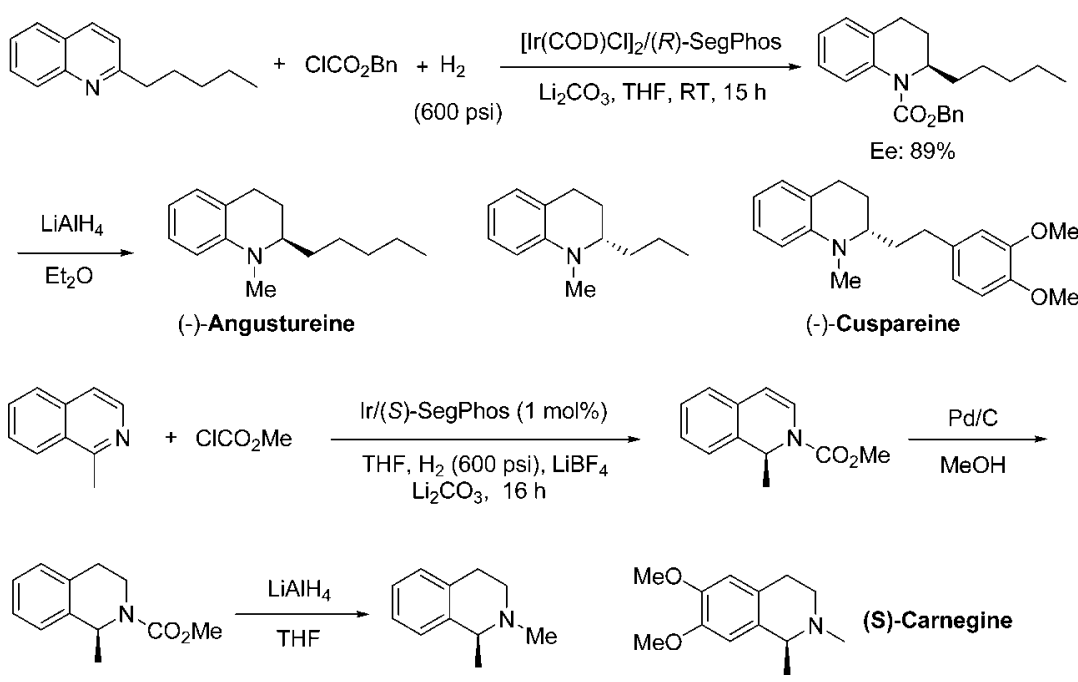

\section{Asymmetric Hydrogenation of Indole Derivatives}

In 2000, Ito and co-workers reported a breakthrough in asymmetric hydrogenation of aromatic compounds in that the hydrogenation of $N$-Boc or Ac-substituted indoles with the use of a $\mathrm{Rh} / \mathrm{Ph}-\mathrm{TRAP} / \mathrm{Cs}_{2} \mathrm{CO}_{3}$ catalyst in isopropanol at $60{ }^{\circ} \mathrm{C}$ is highly effective, and up to $95 \%$ ee was obtained (Scheme 12). ${ }^{25}$ It is noteworthy that both activity and enantioselectivity are significantly dependent upon the use of base. The addition of $10 \mathrm{~mol} \%$ of $\mathrm{Cs}_{2} \mathrm{CO}_{3}$ or $\mathrm{Et}_{3} \mathrm{~N}$ improved enantioselectivity and catalytic activity remarkably. The chiral ligand is crucial for enantioselectivity. Only trans chelating bisphosphine ligand PhTRAP gave a high
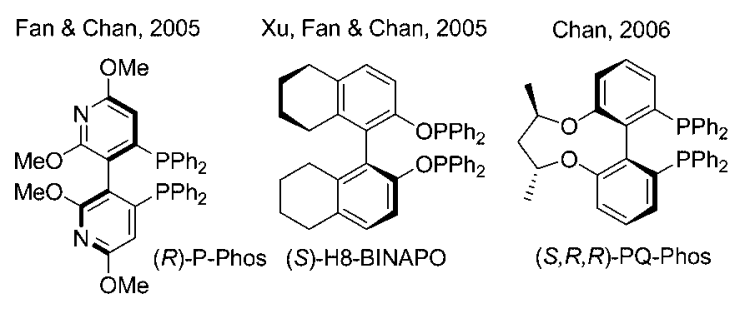

$$
\text { Ee: } 90-92 \%
$$

Ee: $87-97 \%$

Ee: $70-92 \%$

Reetz, $2006 \quad$ Jenet \& Mashima, $2006 \quad$ Xu, Fan \& Chan, 2007<smiles>c1coc2p3c4ccccc4oc=2c(c1)[PH]1(OCCO3)OCCO1</smiles>

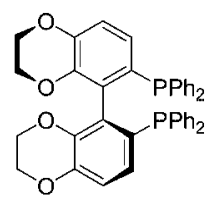

$\mathrm{IrH}(\mathrm{I})(\mathrm{OAC})[(\mathrm{S})-\mathrm{SynPhos}]$

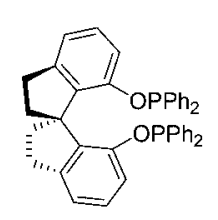

Ee: $73-96 \%$

Ee: $64 \%$ (2-phenylquinoline)

Ee: $65-92 \%$

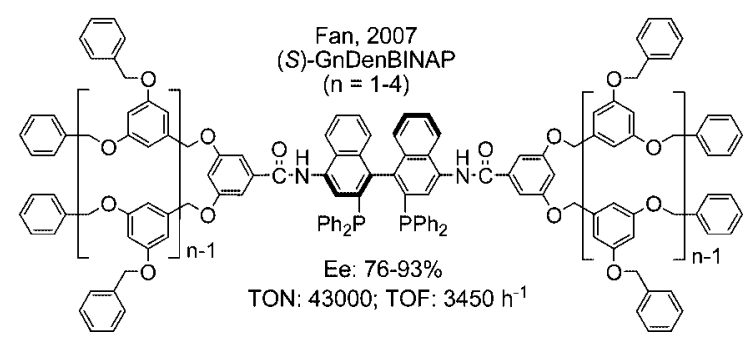

FIGURE 2. Representative chiral bisphosphine ligands used by other research groups. ee, and other commercially available bisphosphine ligands gave almost racemic products. The protecting group (e.g., Ac and Boc) on the nitrogen atom of indole is also important for enantioselecivity, because it acts as a secondary coordinating group. For 3 -substituted $N$-acetylindoles, undesirable alcoholysis intervened. Using Ts as the protecting group, the indole derivatives underwent hydrogenation satisfactorily (high conversion and 95-98\% ee). ${ }^{26}$

Ru-catalyzed asymmetric hydrogenation of $N$-Boc indoles using a readily prepared catalyst, $[\mathrm{RuCl}(p$-cymene)RhTRAP]Cl, was developed by the same group in 2006 with 90-95\% ee (Scheme 13). ${ }^{27}$ 2,3-Disubstituted indoles only furnished moderate enantioselectivity ( $72 \%$ ee).

For the above hydrogenation of indole derivatives, successful factors include (1) the introduction of protecting groups, Ac, Boc, or Ts, which may act as a secondary

Scheme 12. Rh-Catalyzed Asymmetric Hydrogenation of Indoles

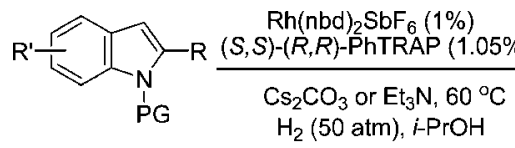<smiles>[R]C1Cc2ccccc2N1[R6]</smiles>

$$
\begin{aligned}
& \mathrm{PG}=\mathrm{Ac}, \mathrm{Boc} \\
& \mathrm{R}=\mathrm{Bu}, \mathrm{i}-\mathrm{Bu}, \mathrm{Ph}, \mathrm{CO}_{2} \mathrm{Me}
\end{aligned}
$$
$\mathbf{R}^{\prime}=5-\mathrm{Me}, 6-\mathrm{MeO}, 6-\mathrm{CF}_{3}$

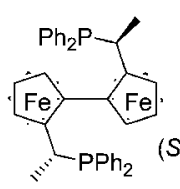

Ee: $78-95 \%$

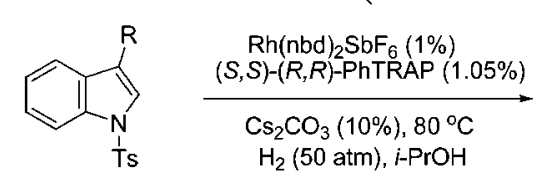

$\mathrm{R}=\mathrm{Me}, i-\mathrm{Pr}, \mathrm{Ph},\left(\mathrm{CH}_{2}\right)_{2} \mathrm{NHBoc},\left(\mathrm{CH}_{2}\right)_{2} \mathrm{CO}_{2} \mathrm{t}-\mathrm{Bu}$

S,S)-(R,R)-PhTRAP

Scheme 13. Ru-Catalyzed Asymmetric Hydrogenation of Indoles

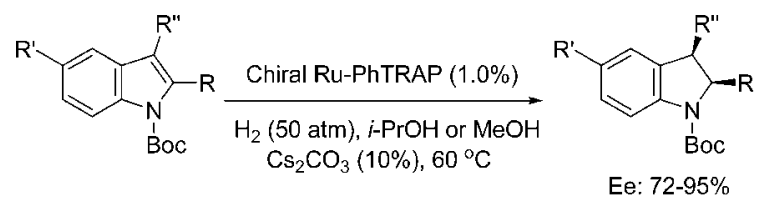

$\mathrm{R}^{\prime}=\mathrm{H}, \mathrm{MeO}, \mathrm{F}$ $\mathrm{R}^{\prime \prime}=\mathrm{H}, \mathrm{Me}, \mathrm{Ph}$

$\mathrm{R}=\mathrm{Me}, \mathrm{Bu}, \mathrm{Ph}, 4-\mathrm{FC}_{6} \mathrm{H}_{4}, \mathrm{CO}_{2} \mathrm{Me}, \mathrm{c}-\mathrm{C}_{6} \mathrm{H}_{11}$ 
Scheme 14. Former Asymmetric Hydrogenation of Pyridines

$$
\text { 然 }
$$

Scheme 15. Asymmetric Hydrogenation of 2-Oxazolidinone-Substituted Pyridines

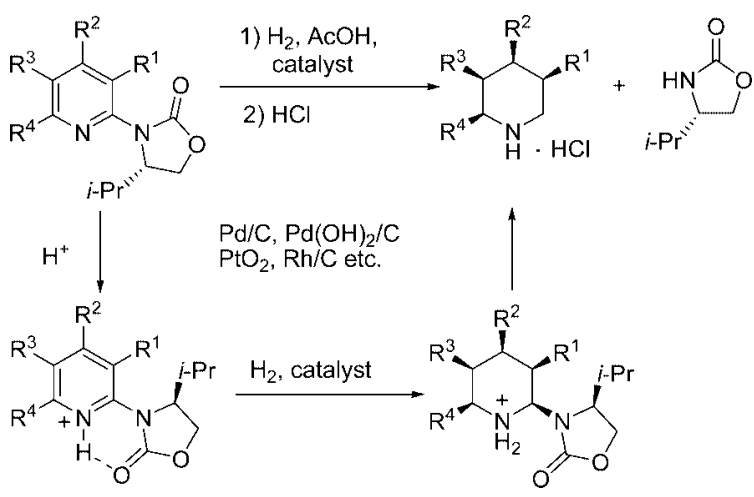

coordinating group or activator of indoles and (2) the addition of a base, which may activate the chiral catalyst, although the reason is not clear.

\section{Asymmetric Hydrogenation of Pyridine Derivatives}

Thousands of pyridine derivatives are commercially available, and numerous others can be prepared by existing methods. In addition, chiral piperidine derivatives are important synthetic intermediates and the structural unit of many biologically active compounds. Therefore, a general method for asymmetric hydrogenation of pyridine derivatives would be highly desirable.

At present, the best results obtained for asymmetric homogeneous hydrogenation of pyridine derivatives is $25 \%$ ee using $5 \mathrm{~mol} \%$ of $\mathrm{Rh}(\mathrm{nbd})_{2} \mathrm{BF}_{4} / \mathrm{BINAP}$ as the catalyst. High temperature and pressure are crucial for full conversion. ${ }^{28} \mathrm{~A}$ cinchona-modified heterogeneous catalyst (up to $19 \%$ ee) was found inefficient (Scheme 14). ${ }^{29}$ Recently, two successful examples on the asymmetric hydrogenation of auxiliary-substituted pyridines ${ }^{30,31}$ and a two-step asymmetric hydrogenation process of 3-substituted pyridines derivatives using a homogeneous rhodium catalyst were reported. ${ }^{32}$

In 2004, Glorius and co-workers reported a highly efficient asymmetric hydrogenation of chiral $\mathrm{N}$-(2-pyridyl)oxazolidinones with up to $98 \%$ ee in acetic acid using commercially available heterogeneous catalysts (Scheme 15). ${ }^{30}$ The substrate is easy to synthesize from 2-bromopyridines and chiral oxazolidinone; the purification procedure is simple; and chiral auxiliary can be conveniently recovered and reused. Products with multiple stereocenters can be prepared in high yield with excellent optically purity. The high diastereoselectivity was ascribed
Scheme 16. Asymmetric Hydrogenation of $\boldsymbol{N}$-Benzoyliminopyridinium Ylides

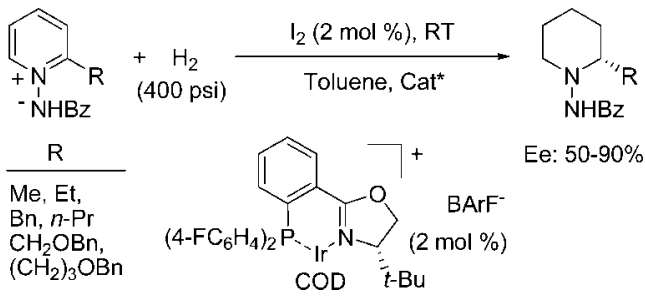

Scheme 17. Hydrogenation Process of 3-Substituted Pyridines

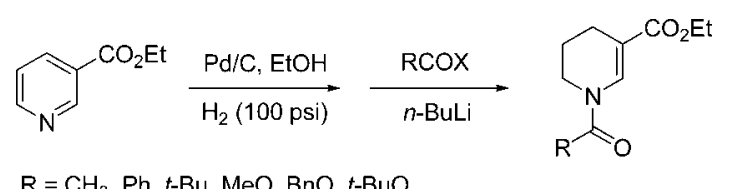

$\mathrm{R}=\mathrm{CH}_{3}, \mathrm{Ph}, t-\mathrm{Bu}, \mathrm{MeO}, \mathrm{BnO}, t-\mathrm{BuO}$

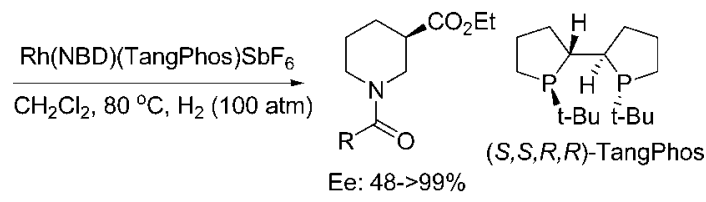

to strong hydrogen bonding between the pyridinium and oxazolidinone moiety in acetic acid.

Charette and co-workers developed an asymmetric hydrogenation of pyridine derivatives with an activating achiral auxiliary and $\mathrm{N}$-benzoyliminopyridinium ylides, with $54-90 \%$ ee (Scheme 16). ${ }^{31} \mathrm{~N}$-Benzoyliminopyridinium ylide acts as the role of the activator of the substrate and secondary coordinating group. The highest enantioselectivities were obtained with cationic iridium complexes of phosphinooxazoline, with tetrakis(3,5-bis(trifluoromethyl)phenyl)borate (BArF) as the counterion. The use of a catalytic amount of iodine is vital to achieve high yields, which may play an activator role for the Ir catalyst. This is a successful example based on the principle of simultaneous activation of the substrate and catalyst. It is well-suited for the asymmetric hydrogenation of 2-substituted $\mathrm{N}$-benzoyliminopyridinium ylides. The hydrogenation adducts obtained can be converted to the corresponding piperidine derivatives using Raney nickel or lithium in ammonia to cleave the N-N bond.

Zhang, Lei, and co-workers reported a highly enantioselective hydrogenation process of ethyl nicotinate, ${ }^{32}$ which consists of an efficient partial hydrogenation of nicotinate with $\mathrm{Pd} / \mathrm{C}$ and a subsequent highly enantioselective homogeneous hydrogenation using Rh(NBD)(TangPhos) $\mathrm{SbF}_{6}$ as the catalyst, with $>99 \%$ ee (Scheme 17).

\section{Asymmetric Hydrogenation of Furan Derivatives}

Hydrogenation of furan derivatives is also less explored. ${ }^{5,28}$ In 2006, two groups reported the efficient asymmetric hydrogenation of furan derivatives (Scheme 18). According to Pfaltz and co-workers, Ir catalysts derived from the pyridine-phosphinite ligand delivered tetrahydrofuran derivatives with $78-99 \%$ ee, ${ }^{33}$ and this is the best result for the asymmetric hydrogenation of furan derivatives to date. The P substituent in the bidentate pyridine-phosphinite ligand is crucial for the enantioselectivity, and the 
Scheme 18. Asymmetric Hydrogenation of Furan Derivatives
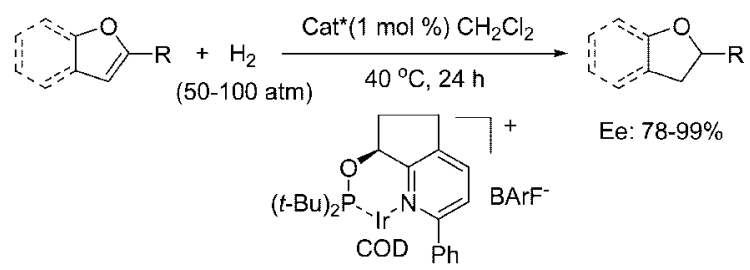

Ee: $78-99 \%$
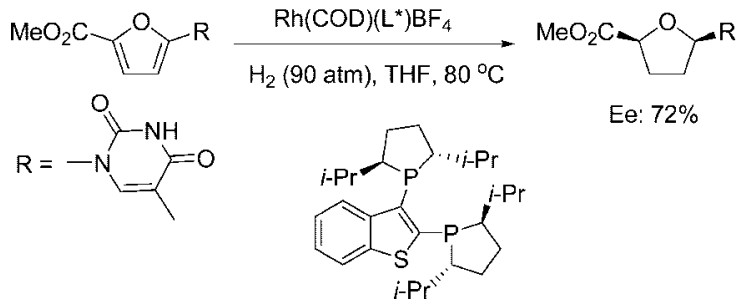

Scheme 19. Pd-Catalyzed Asymmetric Hydrogenation of Activated Imines

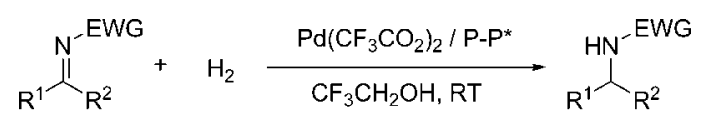<smiles>[R]c1noc2ccccc12</smiles>

Ee: $88-92 \%$

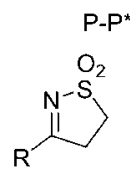

Ee: $79-93 \%$
$-P^{\star}:(S)-S e g P h o s$ or (S)-SynPhos

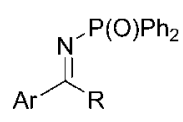

Ee: $87-99 \%$

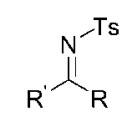

Ee: $88-97 \%$ $t$-butyl group was identified as the best. Albert and coworkers developed a homogeneous asymmetric hydrogenation of 2,5-disubstituted furans, using cationic rhodium bisphosphine complexes, ${ }^{34}$ and up to $72 \%$ ee was obtained.

Studies have shown that a few other heteroaromatic compounds underwent hydrogenation with moderate enantioselectivity. For example, 2-methylquinoxaline can be hydrogenated using Noyori's $\mathrm{RuCl}_{2}$ (bisphosphine) (1,2diamine) catalyst $(73 \% \text { ee })^{35}$ and the $\left[\operatorname{Ir}(\mathrm{COD}) \mathrm{Cl}_{2} / \mathrm{PQ}-\right.$ Phos $/ \mathrm{I}_{2}$ system $(72 \% \text { ee })^{21}$

\section{Miscellaneous Work on Pd-Catalyzed Hydrogenation of Activated Imines}

In the course of exploring the asymmetric hydrogenation of aromatic compounds using the activation strategy, we developed the Pd-catalyzed hydrogenation of activated imines to acquire chiral heterocycles using the $\mathrm{Pd}(\mathrm{O}-$ $\left.\mathrm{COCF}_{3}\right)_{2} /$ diphosphine complex in trifluoroethanol (Scheme 19). ${ }^{36}$ Two kinds of cyclic $N$ - $p$-toluenesulfonyl imines can also be hydrogenated with high enantioselectivity using $\mathrm{Pd}\left(\mathrm{OCOCF}_{3}\right)_{2} /(S)$-SegPhos. ${ }^{36 \mathrm{~b}}$ To our delight, this methodology provides a new access to chiral heterocycle sultam derivatives, which are important synthetic intermediates and structural units for agricultural and pharmaceutical agents. For $N$ - $p$-toluenesulfonyl and $N$-diphenylphospinyl acyclic ketimines, up to $99 \%$ ee can also be obtained using the $\mathrm{Pd}\left(\mathrm{OCOCF}_{3}\right)_{2} /(S)$-SynPhos or $(S)$-SegPhos complex as the catalyst. The exclusive $E$ configuration of the imines and the strong electron-withdrawing character likely contributed to the success of the asymmetric hydrogenation.

\section{Summary and Outlook}

This Account focused on recent advances in homogeneous asymmetric hydrogenations of heteroaromatic compounds. Two different systems were developed for the hydrogenation of quinolines. One is the highly active iridium catalyst $\mathrm{Ir} /$ diphosphine $/ \mathrm{I}_{2}$, in which iodine is a crucial additive for activity and enantioselctvity. The other was $\mathrm{Ir} /$ diphosphine $/ \mathrm{Li}_{2} \mathrm{CO}_{3}$ and involves derivatization to form quinolinium salts with chloroformates. The latter protocol can be applied to the asymmetric hydrogenation of isoquinolines. A highly enantioselective organocatalytic asymmetric transfer hydrogenation of quinolines is to use a chiral BINOL-derived Brønsted acid as the catalyst. Protected indoles can be hydrogenated efficiently using $\mathrm{Rh}$ or $\mathrm{Ru}$ complexes with trans chelating bisphosphines ligands. Pyridine derivatives with chiral and achiral auxiliaries can be efficiently hydrogenated using heterogeneous catalysts and homogeneous Ir/N-P catalysts in the presence of iodine, respectively. Furan derivatives can be hydrogenated with high enantioselectivity using Ir catalysts derived from pyridine-phosphinite.

Although some promising results have been obtained in the asymmetric hydrogenation of aromatic compounds, it should be emphasized that a great deal of effort is required to work out satisfactory protocols for various situations. All of the above examples are confined to bicyclic heteroaromatic compounds possessing quinoline, isoquinoline, quinoxaline, or indole skeletons, in which aromatic stabilization of the heteroaromatic ring is reduced, thus rendering their susceptibility to hydrogenation. For the monocyclic heteroaromatic compounds, only furan derivatives gave the excellent enantioselectivity. Low enantioselectivity was obtained for the direct hydrogenation of pyridine derivatives. The asymmetric hydrogenation of common phenols, anilines, and arenes is largely unsuccessful. Future work may then focus on the following: (1) The development of a new activation strategy for arenes and heteroaromtic compounds; perhaps superacids and Lewis acids deserve a closer look. (2) Exploration of new homogeneous catalysts, containing new combinations of metal precursors, chiral ligands, and additives. (3) Rueping's organcatalytic hydrogenation of quinolines opened a new access to the asymmetric hydrogenation of heteroaromatic compounds; therefore, the design and development of a new organocatalyst type are a good direction because of the compatibility of the functional group and simple operation of the organocatalytic process. $^{37}$ (4) Heterogeneous catalysts capable of asymmetric hydrogenation should also be explored, because their recyclability should be simpler. (5) A fuller understanding of the mechanistic details of these successful reactions might eventually lead to the next generation of general asymmetric hydrogenation methods for aromatic compounds.

The National Natural Science Foundation of China (20532005) and Chinese Academy of Sciences (15020) provided financial support for the research described in this Account. I am very grateful to my co-workers Sheng-Mei Lu, You-Qing Wang, Wen- 
Bo Wang, and Da-Wei Wang for their enthusiasm and hard work, which made this research program successful. I also thank Prof. Tse-Lok Ho and Prof. Shu-Li You for helpful discussion.

\section{References}

(1) For some recent books and reviews, see: (a) Catalytic Asymmetric Synthesis; Ojima, I., Ed.; Wiley-VCH Publishers: New York, 2000. (b) Asymmetric Catalysis in Organic Synthesis; Noyori, R., Ed.; Wiley: New York, 1994. (c) Comprehensive Asymmetric Catalysis; Jacobsen, E. N., Pfaltz, A., Yamamoto, H., Eds.; Springer: Berlin, Germany, 1999; Vol. 1. (d) Lin, G.-Q.; Li, Y.-M.; Chan, A. S. C. Principles and Applications of Asymmetric Synthesis; Wiley and Sons: New York, 2001. (e) Tang, W.; Zhang, X. New Chiral Phosphorus Ligands for Enantioselective Hydrogenation. Chem. Rev. 2003, 103, 3029-3070. (f) Knowles, W. S. Asymmetric Hydrogenation. Angew. Chem., Int. Ed. 2002, 41, 1998-2007. (g) Noyori, R. Asymmetric Catalysis: Science and Opportunities. Angew. Chem., Int. Ed. 2002, 41, 2008-2022.

(2) Bird, C. W. Heteroaromaticity, 5, a Unified Aromaticity Index. Tetrahedron 1992, 48, 335-340.

(3) For recent reviews, see: (a) Glorius, F. Asymmetric Hydrogenation of Aromatic Compounds. Org. Biomol. Chem. 2005, 3, 4171-4175. (b) Lu, S.-M.; Han, X.-W.; Zhou, Y.-G. Recent Advances in Asymmetric Hydrogenation of Hetroaromatic Compounds. Chin. J. Org. Chem. 2005, 25, 634-640. (c) Dyson, P. J. Arene Hydrogenation by Homogeneous Catalysts: Fact or Fiction. Dalton Trans. 2003, 29642974.

(4) Murata, S.; Sugimoto, T.; Matsuura, S. Hydrogenation and Hydrosilylation of Quinoxaline by Homogeneous Rhodium Catalysts. Heterocycles 1987, 26, 763-766.

(5) Ohta, T.; Miyake, T.; Seido, N.; Kumobayashi, H.; Takaya, H. Asymmetric Hydrogenation of Olefins with Aprotic Oxygen Funtionalities Catalyzed by BINAP-Ru(II) Complexes. J. Org. Chem. 1995, 60, 357-363.

(6) Fuchs, R. Process for the Preparation of Optically Active Piperazine2-carboxylic Acid Derivatives, 1997, Eur. Pat. Appl. EP 803502 (Chem. Abstr., 1998, 128, 13286).

(7) Bianchini, C.; Barbaro, P.; Scapacci, G.; Farnetti, E.; Graziani, M. Enantioselective Hydrogenation of 2-Methylquinoxaline to $(-)-(2 S)$ 2-Methyl-1,2,3,4-Tetrahydroquinoxaline by Iridium Catalysis. Organometallics 1998, 17, 3308-3310.

(8) (a) Comprehensive Natural Products Chemistry; Barton, D. H. R., Nakanishi, K., Meth-Cohn, O., Eds.; Elsevier: Oxford, U.K., 1999; Vol. 1-9. (b) Keay, J. D. In Comprehensive Organic Synthesis; Trost, B. M., Fleming, I., Eds.; Pergamon: Oxford, U.K., 1991; Vol. 8, pp 579-601. (c) Katritzky, A. R.; Rachwal, S.; Rachwal, B. Recent Progress in the Synthesis of 1,2,3,4-Tetrahydroquinolines. Tetrahedron 1996, 52, 15031-15070.

(9) Vogl, E. M.; Groger, H.; Shibasaki, M. Towards Perfect Asymmetric Catalysis: Additives and Cocatalysts. Angew. Chem., Int. Ed. 1999, 38, 1570-1577.

(10) (a) Togni, A. Planar-Chiral Ferrocenes: Synthetic Methods and Applications. Angew. Chem., Int. Ed. 1996, 35, 1475-1477. (b) Xiao, D.; Zhang, X. Highly Enantioselective Hydrogenation of Acyclic Imines Catalyzed by Ir-f-Binaphane Complexes. Angew. Chem., Int. Ed. 2001, 40, 3425-3428. (c) Dorta, R.; Broggini, D.; Stoop, R.; Ruegger, H.; Spindler, F.; Togni, A. Chiral Xyliphos Complexes for the Catalytic Imine Hydrogenation Leading to the Metolachlor Herbicide: Isolation of Catalyst-Substrate Adducts. Chem.-Eur. J. 2004, 10, 267-278. (d) Hou, G.-H.; Xie, J.-H.; Wang, L.-X.; Zhou, Q.-L. Highly Efficient Rh(I)-Catalyzed Asymmetric Hydrogenation of Enamines Using Monodente Spiro Phosphonite Ligands. J. Am. Chem. Soc. 2006, 128, 11774-11775.

(11) Wang, W.-B.; Lu, S.-M.; Yang, P.-Y.; Han, X.-W.; Zhou, Y.-G. Highly Enantioselective Iridium-Catalyzed Hydrogenation of Heteroaromatic Compounds, Quinolines. J. Am. Chem. Soc. 2003, 125, 10536-10537.

(12) (a) Lu, S.-M.; Han, X.-W.; Zhou, Y.-G. Asymmetric Hydrogenation of Quinolines Catalyzed by Iridium with Chiral Ferrocenyloxazoline Derived N,P Ligands. Adv. Synth. Catal. 2004, 346, 909-912. (b) Zhao, Y.-J.; Wang, Y.-Q.; Zhou, Y.-G. Application of FerroceneDerived Chiral S,P-Donor Ligands for Iridium-Catalyzed Asymmetric Hydrogenation of Quinolines. Chin. J. Catal. 2005, 26, 737739. (c) Lu, S.-M.; Wang, Y.-Q.; Zhou, Y.-G. An Efficient Catalytic System for the Hydrogenation of Quinolines. J. Organometal. Chem. 2007, 692, 3065-3069.

(13) Yang, P.-Y.; Zhou, Y.-G. The Enantioselective Total Synthesis of Alkaloid (-)-Galipeine. Tetrahedron: Asymmetry 2004, 15, 1145-1149.

(14) For recent representative examples, see (a) Tuttle, J. B.; Ouellet, S. G.; MacMillan, D. W. C. Organocatalytic Transfer Hydrogenation of Cyclic Enones. J. Am. Chem. Soc. 2006, 128, 12662-12663. (b)
Martin, N. J. A.; List, B. Highly Enantioselective Transfer Hydrogenation of $\alpha, \beta$-Unsaturated Ketones. J. Am. Chem. Soc. 2006, 128, 13368-13369. (c) Hoffmann, S.; Nicoletti, M.; List, B. Catalytic Asymmetric Reductive Amination of Aldehydes via Dynamic Kinetic Resolution. J. Am. Chem. Soc. 2006, 128, 13074-13075. (d) Rueping, M.; Antonchick, A. P.; Theissmann, T. Remarkably Low Catalyst Loading in Brønsted Acid Catalyzed Transfer Hydrogenations: Enantioselective Reduction of Benzoxazines, Benzothiazines, and Benzoxazinones. Angew. Chem., Int. Ed. 2006, 45, 6751-6755. (e) Ouellet, S. G.; Tuttle, J. B.; MacMillan, D. W. C. Enantioselective Organocatalytic Hydride Reduction. J. Am. Chem. Soc. 2005, 127, 32-33. (f) Storer, R. I.; Carrera, D. E.; Ni, Y.; MacMillan, D. W. C. Enantioselective Organocatalytic Reductive Amination. J. Am. Chem. Soc. 2006, 128, 84-86. (g) Rueping, M.; Sugiono, E.; Azap, C.; Theissmann, T.; Bolte, M. Enantioselective Brønsted Acid Catalyzed Transfer Hydrogenation: Organocatalytic Reduction of Imines. Org. Lett. 2005, 7, 3781-3783, and references cited therein.

(15) Rueping, M.: Antonchick, A. P.: Theissmann, T. A Highly Enantioselective Bronsted Acid Catalyzed Cascade Reaction: Organocatalytic Transfer Hydrogenation of Quinolines and Their Application in the Synthesis of Alkaloids. Angew. Chem., Int. Ed. 2006, 45, 3683-3686.

(16) Lu, S.-M.; Wang, Y.-Q.; Han, X.-W.; Zhou, Y.-G. Homogeneous Iridium-Catalyzed Dehydroaromatization of 2-Substituted-1,2-dihydroquinolines. Chin. J. Catal. 2005, 26, 287-290.

(17) Wang, D.-W.; Zeng, W.; Zhou, Y.-G. Iridium-Catalyzed Asymmetric Transfer Hydrogenation of Quinolines with Hantzsch Esters. Tetrahedron: Asymmetry 2007, 11, 1103-1107.

(18) Lu, S.-M.; Wang, Y.-Q.; Han, X.-W.; Zhou, Y.-G. Asymmetric Hydrogenation of Quinolines and Isoquinolines Activated by Chloroformates. Angew. Chem., Int. Ed. 2006, 45, 2260-2263.

(19) (a) Xu, L.; Lam, K. H.; Ji, J.; Wu, J.; Fan, O.-H.; Lo, W.-H.; Chan, A. S. C. Air-Stable Ir-(P-Phos) Complex for Highly Enantioselective Hydrogenation of Quinolines and Their Immobilization in Poly(ethylene glycol) Dimethyl Ether (DMPEG). Chem. Commun. 2005, 1390-1392. (b) Wu, J.; Chan, A. S. C. P-Phos: A Family of Versatile and Effective Atropisomeric Dipyridylphosphine Ligands in Asymmetric Catalysis. Acc. Chem. Res. 2006, 39, 711-720.

(20) (a) Lam, K. H.; Xu, L.; Feng, L.; Fan, Q.-H.; Lam, F. L.; Lo, W.-H.; Chan, A. S. C. Highly Enantioselective Iridium-Catalyzed Hydrogenation of Quinoline Derivatives Using Chiral Phosphinite H8BINAPO. Adv. Synth. Catal. 2005, 347, 1755-1758. (b) Tang, W.-J.; Zhu, S.-F.; Xu, L.-J.; Zhou, Q.-L.; Fan, Q.-H.; Zhou, H.-F.; Lam, K.; Chan, A. S. C. Asymmetric Hydrogenation of Quinolines with High Substrate/Catalyst Ratio. Chem. Commun. 2007, 613-615.

(21) Qiu, L.; Kwong, F. Y.; Wu, J.; Lam, W. H.; Chan, S.; Yu, W. Y.; Li, Y.-M.; Guo, R.; Zhou, Z.; Chan, A. S. C. A New Class of Versatile Chiral-Bridge Atropisomeric Diphosphine Ligands: Remarkably Efficient Ligand Syntheses and Their Applications in Highly Enantioselective Hydrogenation Reactions. J. Am. Chem. Soc. 2006, 128, 5955-5965.

(22) Reetz, M. T.; Li, X. Asymmetric Hydrogenation of Quinolines Catalyzed by Iridium Complexes of BINOL-Derived Diphosphonites. Chem. Commun. 2006, 2159-2160.

(23) Wang, Z.-J.; Deng, G.-J.; Li, Y.; He, Y.-M.; Tang, W.-J.; Fan, Q.-H. Enantioselective Hydrogenation of Quinolines Catalyzed by $\operatorname{Ir}(\mathrm{BI}-$ NAP)-Cored Dendrimers: Dramatic Enhancement of Catalytic Activity. Org. Lett. 2007, 9, 1243-1246.

(24) Yamagata, T.; Tadaoka, H.; Nagata, M.; Hirao, T.; Kataoka, Y.; Ratovelomanana-Vidal, V.; Genet, J. P.; Mashima, K. Oxidative Addition of $\mathrm{RCO}_{2} \mathrm{H}$ and $\mathrm{HX}$ to Chiral Diphosphine Complexes of Iridium(I): Convenient Synthesis of Mononuclear Halo-carboxylate Iridium(III) Complexes and Their Catalytic Performance in Asymmetric Hydrogenation of Cyclic Imines and 2-Phenylquinoline. Organometallics 2006, 25, 2505-2513.

(25) (a) Kuwano, R.; Sato, K.; Kurokawa, T.; Karube, D.; Ito, Y. Catalytic Asymmetric Hydrogenation of Heteroaromatic Compounds, Indoles. J. Am. Chem. Soc. 2000, 122, 7614-7615. (b) Kuwano, R.; Kashiwabara, M.; Sato, K.; Ito, T.; Kaneda, K.; Ito, Y. Catalytic Asymmetric Hydrogenation of Indoles Using a Rhodium Complex with A Chiral Bisphosphine Ligand PhTRAP. Tetrahedron: Asymmetry 2006, 17, 521-535.

(26) Kuwano, R.; Kaneda, K.; Ito, T.; Sato, K.; Kurokawa, T.; Ito, Y. Highly Enantioselective Synthesis of Chiral 3-Substituted Indolines by Catalytic Asymmetric Hydrogenation of Indoles. Org. Lett. 2004, 6, 2213-2215.

(27) Kuwano, R.; Kashiwabara, M. Ruthenium-Catalyzed Asymmetric Hydrogenation of N-Boc-Indoles. Org. Lett. 2006, 8, 2653-2655.

(28) Studer, M.; Wedemeyer-Exl, C.; Spindler, F.; Blaser, H.-U. Enantioselective Homogeneous Hydrogenation of Monosubstituted Pyridines and Furans. Monatsh. Chem. 2000, 131, 1335-1343.

(29) (a) Blaser, H.-U.; Honig, H.; Studer, M.; Wedemeyer-Exl, C. Enantioselective Synthesis of Ethyl Nipecotinate Using Cinchona Modified Heterogeneous Catalysts. J. Mol. Catal. A: Chem. 1999, 139, 
253-257. (b) Raynor, S. A.; Thomas, J. M.; Raja, R.; Johnson, B. F. G.; Bell, R. G.; Mantle, M. D. A One-Step, Enantioselective Reduction of Ethyl Nicotinate to Ethyl Nipecotinate Using a Constrained, Chiral, Heterogeneous Catalyst. Chem. Commun. 2000, 1925-1926. For recent reviews, see (c) Studer, M.; Blaser, H.U.; Exner, C. Enantioselective Hydrogenation Using Heterogeneous Modified Catalysts: An Update. Adv. Synth. Catal. 2003, 345, 45-65. (d) Li, C. Chiral Synthesis on Catalysts Immobilized in Microporous and Mesoporous Materials. Catal. Rev. 2004, 46, 419-492.

(30) Glorius, F.; Spielkamp, N.; Holle, S.; Goddard, R.; Lehmann, C. W. Efficient Hydrogenation of Pyridines. Angew. Chem., Int. Ed. 2004, $43,2850-2852$

(31) Legault, C. Y.; Charette, A. B. Catalytic Asymmetric Hydrogenation of $N$-Iminopyridinium Ylides: Expedient Approach to Enantioenriched Substituted Piperidine Derivatives. J. Am. Chem. Soc. 2005, 127, 8966-8967.

(32) Lei, A.; Chen, M.; He, M.; Zhang, X. Asymmetric Hydrogenation of Pyridines: Enantioselective Synthesis of Nipecotic Acid Derivatives. Eur. J. Org. Chem. 2006, 4343-4347.

(33) Kaiser, S.; Smidt, S. P.; Pfaltz, A. Iridium Catalysts with Bicyclic Pyridine-Phosphinite Ligands: Asymmetric Hydrogenation of Olefins and Furan Derivatives. Angew. Chem., Int. Ed. 2006, 45, 5194-5197.
(34) Feiertag, P.; Albert, M.; Nettekoven, U.; Spindler, F. Asymmetric Homogeneous Hydrogenation of 2,5-Disubstituted Furans. Org. Lett. 2006, 8, 4133-4135.

(35) Henschke, J. P.: Burk, M. J.; Malan, C. G.; Herzberg, D.; Peterson, J. A.; Wildsmith, A. J.; Cobley, C. J.; Casy, G. Synthesis and Applications of HexaPHEMP, a Novel Biaryl Diphosphine Ligand. Adv. Synth. Catal. 2003, 345, 300-307.

(36) (a) Wang, Y.-O.; Zhou, Y.-G. Highly Enantioselective Pd-Catalyzed Asymmetric Hydrogenation of $\mathrm{N}$-Diphenylphosphinyl-ketimines. Synlett. 2006, 1189-1192. (b) Wang, Y.-Q.; Lu, S.-M.; Zhou, Y.-G. Highly Enantioselective Palladium-Catalyzed Asymmetric Hydrogenation of Activated Imines. J. Org. Chem. 2007, 72, 3729-3734. For the Pd-catalyzed asymmetric hydrogenation of $\mathrm{N}$-tosylimines using $\mathrm{Pd} /$ TangPhos in dichloromethane, see (c) Yang, Q.; Shang, G.; Gao, W.; Deng, J.; Zhang, X. A Highly Enantioselective PdTangPhos-Catalyzed Hydrogenation of $\mathrm{N}$-Tosylimines. Angew. Chem., Int. Ed. 2006, 45, 3832-3835.

(37) Rueping, M.; Antonchick, A. P. Organocatalytic Enantioselective Reduction of Pyridines. Angew. Chem., Int. Ed. 2007, 46, 4562-4563.

AR700094B 